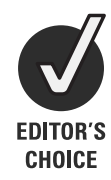

${ }^{1}$ Department of Rheumatology, Leiden University Medical

Center, Leiden, The Netherlands 2Department of Rheumatology, AVU Amsterdam, Amsterdam, The Netherlands

${ }^{3}$ Department of Rheumatology, Atrium Medical Center Heerlen, Heerlen, The Netherlands ${ }^{4}$ Paris-Descartes University, Paris, France

${ }^{5}$ Department of Rheumatology, Cochin Hospital, Paris, France

\section{Correspondence to}

Désirée van der Heijde Leiden University Medical

Center, Rheumatology,

P0 Box 9600, 2300 RC Leiden,

The Netherlands:

mail@dvanderheijde.nl

Accepted 7 March 2012

\title{
Continuous NSAID use reverts the effects of in ammation on radiographic progression in patients with ankylosing spondylitis
}

\author{
Féline Kroon, ${ }^{1}$ Robert Landewé, ${ }^{2,3}$ Maxime Dougados, ${ }^{4,5}$ Désirée van der Heijde ${ }^{1}$
}

\begin{abstract}
Objectives The aim was to compare continuous and on-demand NSAID treatment with respect to their ability to suppress radiographic progression in subgroups of patients with high/elevated CRP-levels, ESR, ASDASlevels or BASDAI-levels in comparison to patients with normal levels.

Methods Post-hoc analyses were performed in a randomized trial comparing continuous and on-demand NSAID treatment. Relevant high/elevated subgroups were created based on time-averaged (ta) CRP ( $>5 \mathrm{mg} / \mathrm{L})$, ta-ESR (>12mm/hr), ta-BASDAI (>4), ta-ASDAS-CRP (>2.1) and ta-ASDAS-ESR (>2.1). Subgroups were further split according to NSAID-use (continuous vs. on-demand). Radiological progression was presented in probability plots. Statistical interactions were tested using multiple and logistic regression analysis. Differences in radiological progression were analysed using the Chisquare and Mann-Whitney U test.
\end{abstract}

Results 150 participants randomized to either the continuous-treatment group ( $n=76)$, or the on-demand group $(n=74)$ had complete radiographs and were included. The effect of slowing radiological progression with continuous NSAID therapy was more pronounced in patients with elevated ta-CRP-levels, elevated ta-ESR, high ta-ASDAS-CRP or high ta-ASDAS-ESR versus patients with low/normal values. No such effect was found for participants with high vs. Iow BASDAI. Also, in participants with elevated ta-ESR (irrespective of treatment), there appeared to be a higher rate of structural progression than in participants with normal ta-ESR. Regression analyses showed that continuous NSAID treatment neutralizes the negative effect of inflammation (high ta-ESR).

Conclusions Patients with elevated acute phase reactants seem to benefit most from continuous treatment with NSAIDs. Continuous NSAID-therapy in patients with elevated acute phase reactants may lead to an improved benefit-risk-ratio of these drugs.

\section{INTRODUCTION}

Ankylosing spondylitis (AS) may cause syndesmophyte formation and fusion in a substantial proportion of patients. These processes can lead to impaired spinal mobility, which in turn decreases the patient's ability to perform daily activities and may severely impair quality of life. ${ }^{1}$ Therefore, it is an important goal in the treatment of AS to prevent progression of structural damage of the spine. $^{2}$
It was shown by us in a clinical trial that continued treatment with non-steroidal anti-inflammatory drugs (NSAIDs), in comparison with on-demand use of NSAIDs, reduced radiological progression in the spine in patients with AS. ${ }^{3}$ This finding has recently been confirmed in an observational cohort study, GErman SPondyloarthiritis Inception Cohort (GESPIC). ${ }^{4}$

Predictors of radiological progression in AS are scarce. It has been proven convincingly that patients with radiological damage at baseline will progress over time in comparison with patients without baseline damage. ${ }^{5}$ Further, it was shown by us that matrix-metalloproteinase- 3 is an independent predictor of radiographic progression. ${ }^{6}$ Recently, in the GESPIC cohort as well as in a Canadian study, elevated $C$ reactive protein (CRP) levels have also shown to be a positive predictor of radiological progression. ${ }^{7}$ Finally, it was shown that high functional levels of dickkopf-1 may protect against syndesmophyte formation. ${ }^{9}$ The most important factors influencing radiological progression in AS are still to be identified. Further, different clinical trials have failed to show inhibition of structural damage by tumour necrosis factor (TNF) $\alpha$-blocking drugs ${ }^{10-12}$ in spite of their effects on both signs and symptoms and acute phase reactants. All together, these findings suggest a possible role for NSAID therapy as adjuncts to TNF-blocking drugs.

Chronic NSAID use in general is feared for its gastrointestinal and cardiovascular toxicities, and it is preferred to prescribe NSAIDs only for short periods of time and in the lowest possible dose. In AS, however, NSAIDs are recommended as firstline drug treatment in a full anti-inflammatory dose, and patients are frequently advised to take this medication for longer periods of time. ${ }^{2}$ But once patients are started on TNF-blocking drugs, NSAIDs are often reduced in dose, prescribed 'on-demand' only, or withdrawn completely.

Now there may be reasons unrelated to the inhibition of signs and symptoms to prescribe NSAIDs in a continuous way, it is crucial to understand which patients may have the most to gain from continuous NSAID use in terms of radiological progression. In rheumatoid arthritis, treat-totarget guidelines have been formulated that aim at abrogation of inflammation in order to prevent structural damage, thus normalising function and optimising health-related quality of life. ${ }^{13}$ In AS, such a target is more difficult to determine because 
there is no evident relationship among signs and symptoms and radiological damage. ${ }^{14}$ This gives rise to the question if there is any measure that potentially could define such a target.

Here we present post hoc analyses of the previously mentioned clinical trial that compared continuous NSAID treatment and on-demand NSAID treatment with respect to their ability to suppress radiographic progression in subgroups of patients with high CRP levels, high erythrocyte sedimentation rate (ESR) levels, high ankylosing spondylitis disease activity score (ASDAS) levels or high Bath ankylosing spondylitis disease activity index (BASDAI) levels.

\section{METHODS}

\section{Study design}

The design of the trial has been reported elsewhere. ${ }^{3}$ In brief, patients with AS who had previously participated in a 6-week randomised, double-blind, placebo-controlled trial comparing ketoprofen and celecoxib ${ }^{15}$ were asked to join the trial. Patients were randomised to either a continuous-treatment arm, with daily NSAID treatment irrespective of symptoms for a period of 2 years, or an on-demand treatment arm, with the instruction to take their NSAID only when they had serious symptoms (eg, pain or stiffness). All patients started on celecoxib $200 \mathrm{mg}$ daily but were allowed to increase the dose or change NSAID treatment but had to continue to use the NSAIDs according to the continuous or on-demand strategy.

\section{Study visits}

Study visits were planned at the following time points: baseline, a follow-up visit after 1 month, 7 follow-up visits each after 3 months intervals and a final visit at 24 months. At every visit, clinical signs and symptoms were assessed, as well as adverse events. Laboratory tests were performed in the local lab during the visits at baseline, months 1, 7, 13, 19 and 24. Radiographs of the spine were taken at baseline and at 24 months.

\section{Outcomes assessed}

Several outcomes were assessed of which the following were used in the analyses: clinical disease activity (using the BASDAI) and inflammation (using CRP (mg/l) and ESR $(\mathrm{mm} / \mathrm{h})){ }^{16}$ Structural damage was scored on radiographs using the modified Stoke Ankylosing Spondylitis Spine Score (mSASSS) performed by a single observer who was blinded to the treatment strategy and the time order of the radiographs. ${ }^{17}$ The difference between the modified SASSS at month 0 and month 24 was considered the progression score (range: 0-72 mSASSS units).

Disease activity was also expressed using the ASDAS, an outcome not used in the original trial. The ASDAS combines five disease activity variables (three items from the BASDAI, the patient global level of disease activity, and inflammation measured using either CRP or ESR) resulting in two scores, ASDAS-CRP and ASDAS-ESR. ${ }^{18}$ Cut-offs for disease activity separate 'inactive disease activity' (score $\leq 1.3)$, 'moderate disease activity' (>1.3- $\leq 2.1)$, 'high disease activity' $(>2.1-\leq 3.5)$ and 'very high disease activity' (>3.5). ${ }^{19}$ Furthermore, timeaveraged (ta) values of CRP, ESR, BASDAI, ASDAS-CRP and ASDAS-ESR were calculated using the mean of values measured at all available time points except baseline, providing an overall level of inflammation (for CRP and ESR) or an overall level of disease activity (for BASDAI, ASDAS-CRP and ASDAS-ESR).

\section{Statistical analyses}

Statistical software package PASW-statistics V.18.0 was used for analysis. Radiological progression scores were presented per subgroup of interest in probability plots. ${ }^{20}$ Relevant subgroups were created by splitting ta-CRP, ta-ESR, ta-BASDAI, ta-ASDAS-CRP and ta-ASDAS-ESR at predefined values considered as elevated (for the acute phase reactants and representing high and low disease activity for the disease activity measures) ('low' vs 'high'). CRP levels $>5 \mathrm{mg} / \mathrm{l}$ and ESR $>12 \mathrm{~mm} / \mathrm{h}$ were considered elevated; BASDAI $>4$ and ASDAS $>2.1$ were considered high. These subgroups were further split according to NSAID use (comparing continuous use with on-demand use). Statistical interactions between subgroups of disease activity and mode of NSAID use, as well as their independent contributory effects, on radiographic progression were tested using multiple regression analysis and logistic regression analysis. In the linear regression analysis, mSASSS change scores were normalised using a van der Waerden transformation. In the logistic regression analysis, change in mSASSS was tested at a cut-off level of 2 units/year. Differences in radiological progression between groups were analysed using the $\chi^{2}$ test for the proportion of patients showing progression $\geq 2$ units in $\mathrm{mSASSS}$ and the Mann-Whitney $U$ test for the continuous progression in mSASSS.

\section{RESULTS \\ Patient characteristics at baseline}

Baseline characteristics of the trial have been published previously. ${ }^{3}$ In brief, 215 participants were included and randomised to either the continuous-treatment group $(n=111)$ or the ondemand group $(n=104)$; one patient randomised to the ondemand group died in a car accident before start of the trial. Complete sets of radiographs were available for 76 patients in the continuous-treatment group and for 74 patients in the ondemand group. The baseline characteristics of study participants are shown in table 1 for all randomised patients and for patients with complete radiographs. In total, $67.8 \%$ of the patients show an elevated CRP, $52 \%$ an elevated ESR, $28 \%$ an elevated BASDAI, $50.7 \%$ fall in the category of high/very high disease activity according to ASDAS-CRP and $44.7 \%$ according to ASDAS-ESR. Between-group differences at baseline were small and negligible. The previous publication described detailed reasons for drop out. About $73 \%$ of the patients in both groups used celecoxib during the entire study period.

\section{Probability plots}

In figure $1 \mathrm{~A}$ we compared the radiological progression of participants with normal ta-CRP levels $(\leq 5 \mathrm{mg} / \mathrm{l})$ with the

Table 1 Baseline characteristics by treatment group

\begin{tabular}{|c|c|c|c|c|}
\hline & \multicolumn{2}{|c|}{ All patients } & \multicolumn{2}{|c|}{$\begin{array}{l}\text { Patients with a } \\
\text { complete set of } x \text {-rays }\end{array}$} \\
\hline & $\begin{array}{l}\text { Continuous } \\
\text { use } \\
(n=111)\end{array}$ & $\begin{array}{l}\text { On-demand } \\
\text { use } \\
(n=103)\end{array}$ & $\begin{array}{l}\text { Continuous } \\
\text { use }(n=76)\end{array}$ & $\begin{array}{l}\text { On-demand } \\
\text { use }(n=74)\end{array}$ \\
\hline $\begin{array}{l}\text { Age, mean } \pm S D \\
\text { (years) }\end{array}$ & $38.0 \pm 10.7$ & $40.1 \pm 10.5$ & $40.9 \pm 9.8$ & $37.9 \pm 11.9$ \\
\hline Male (\%) & 67 & 72 & 66 & 70 \\
\hline $\begin{array}{l}\text { Disease duration, } \\
\text { mean } \pm S D \text { (years) }\end{array}$ & $11.9 \pm 9.3$ & $11.0 \pm 9.4$ & $13.0 \pm 10.2$ & $10.2 \pm 9.3$ \\
\hline $\begin{array}{l}\text { Human Leukocyte } \\
\text { Antigen B27 } \\
\text { (HLA-B27) } \\
\text { positive (\%) }\end{array}$ & 86 & 87 & 88 & 88 \\
\hline
\end{tabular}



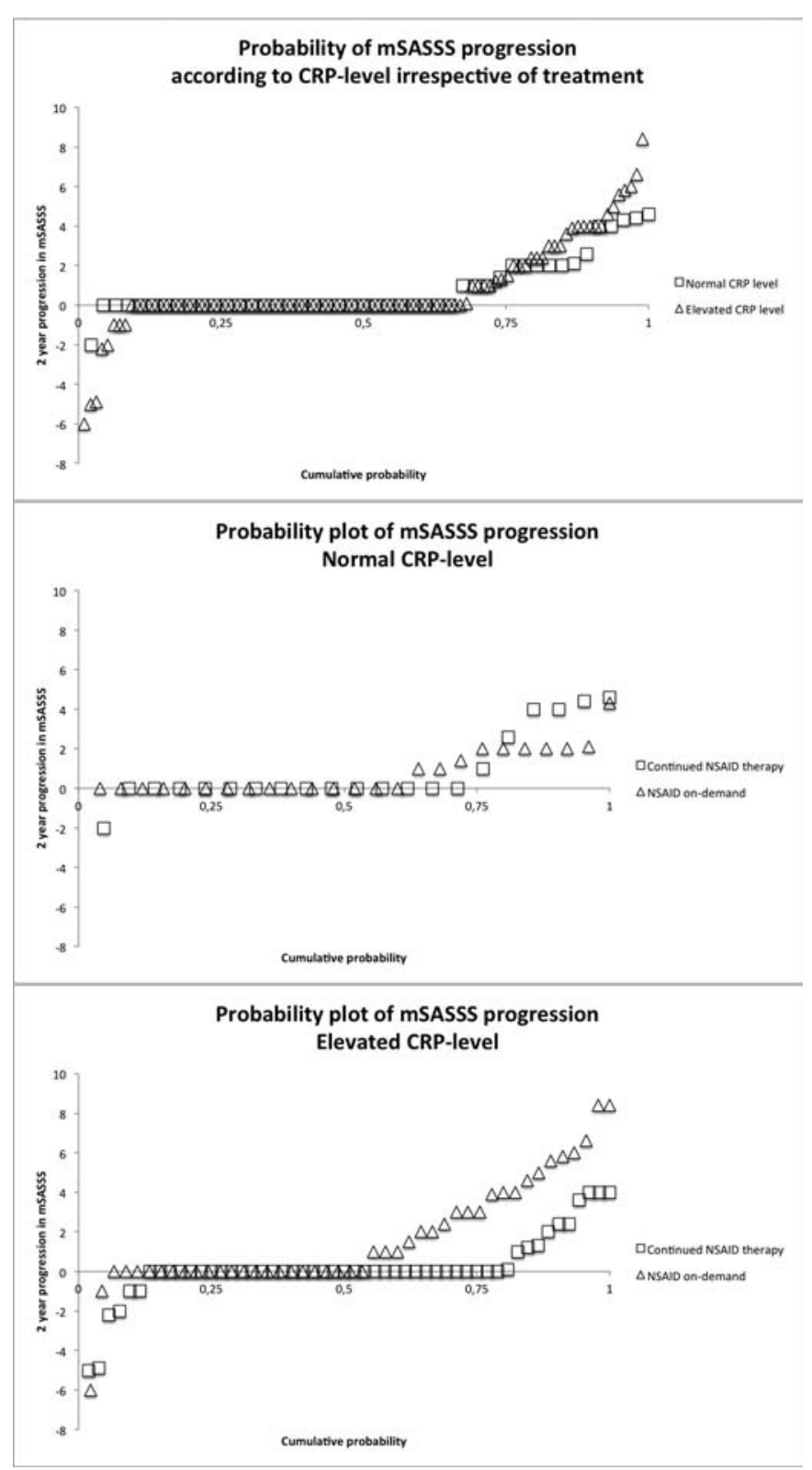

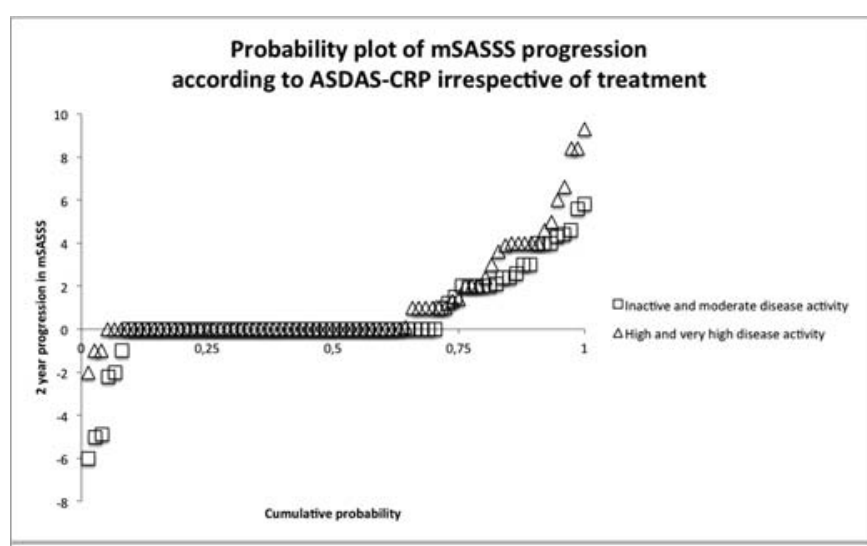

Probability plot of mSASSS progression LoW ASDAS-CRP

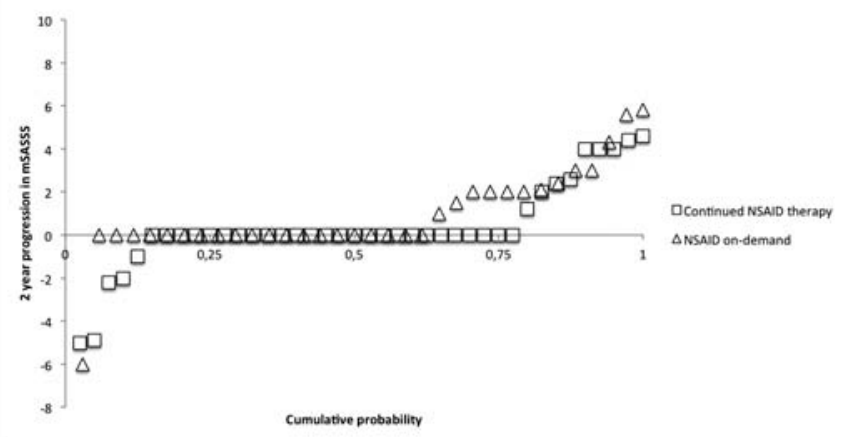

Probability plot of mSASSS progression High ASDAS-CRP

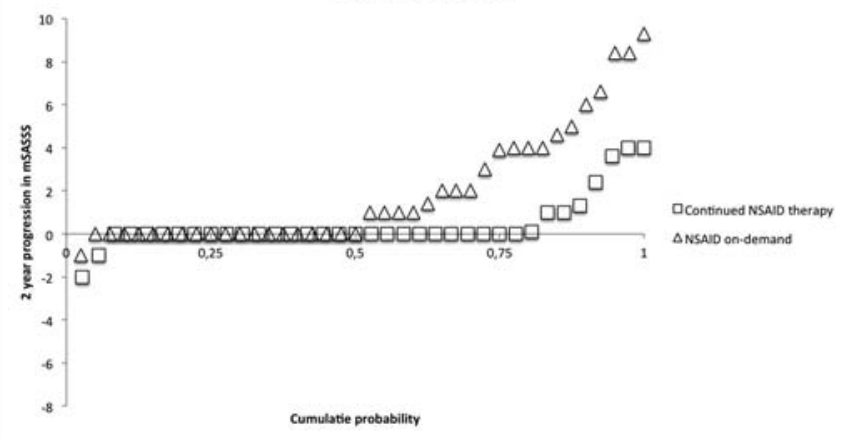

Figure 1 (A) Probability plots of difference in radiological progression among (I) participants with normal $(\leq 5 \mathrm{mg} / \mathrm{l})$ and elevated (>5 mg/l) C reactive protein (CRP) levels irrespective of non-steroidal anti-in ammatory drug (NSAID) treatment group, (II) participants with normal CRP levels and continued NSAID or on-demand NSAID therapy and (III) participants with elevated CRP levels and continued NSAID or on-demand NSAID therapy. (B) Probability plots of difference in radiological progression among (I) participants with low $(\leq 2.1)$ and high ( $>2.1)$ disease activity according to ASDAS-CRP irrespective of treatment, (II) participants with low ankylosing spondylitis disease activity score (ASDAS)-CRP and continued NSAID or on-demand NSAID therapy and (III) participants with high ASDAS-CRP and continued NSAID or on-demand NSAID therapy. (C) Probability plots of difference in radiological progression among (I) participants with low $(\leq 3)$ and high $(>3)$ Bath ankylosing spondylitis disease activity index (BASDAI) irrespective of treatment, (II) participants with low BASDAI and continued NSAID or on-demand NSAID therapy and (III) participants with high BASDAI and continued NSAID or on-demand NSAID therapy. (D) Probability plots of difference in radiological progression among (I) participants with normal $(\leq 12 \mathrm{~mm} / \mathrm{h})$ and elevated ( $>12 \mathrm{~mm} / \mathrm{h}$ ) erythrocyte sedimentation rate (ESR) irrespective of treatment, (II) participants with normal ESR and continued NSAID or on-demand NSAID therapy and (III) participants with elevated ESR and continued NSAID or on-demand NSAID therapy. (E) Probability plots of difference in radiological progression among (I) participants with low $(\leq 2.1)$ and high $(>2.1)$ disease activity according to ASDAS-ESR irrespective of treatment, (II) participants with low ASDAS-ESR and continued NSAID or on-demand NSAID therapy and (III) participants with high ASDAS-ESR and continued NSAID or on-demand NSAID therapy. mSASSS, modi ed Stoke Ankylosing Spondylitis Spine Score.

radiological progression ofparticipantswithelevated ta-CRPlevels ( $>5 \mathrm{mg} / \mathrm{l}$ ), irrespective of their treatment. Progression of structural damage was roughly similar in both CRP groups, with a trend towards more progression in the CRP high group. However, if these CRP groups were further stratified according to their treatment allocation (continuous NSAID therapy or NSAID use on-demand), it is obvious that patients in the CRP high group on continuous NSAID therapy have less radiological progression than patients in the CRP high group using NSAIDs on-demand only. Importantly, this separation was almost absent in the CRP low group.

The effect of ta-ASDAS-CRP (figure 1B) on radiographic progression was similarly modified by treatment mode as the effect of ta-CRP on radiographic progression. The effect of ta-BASDAI 


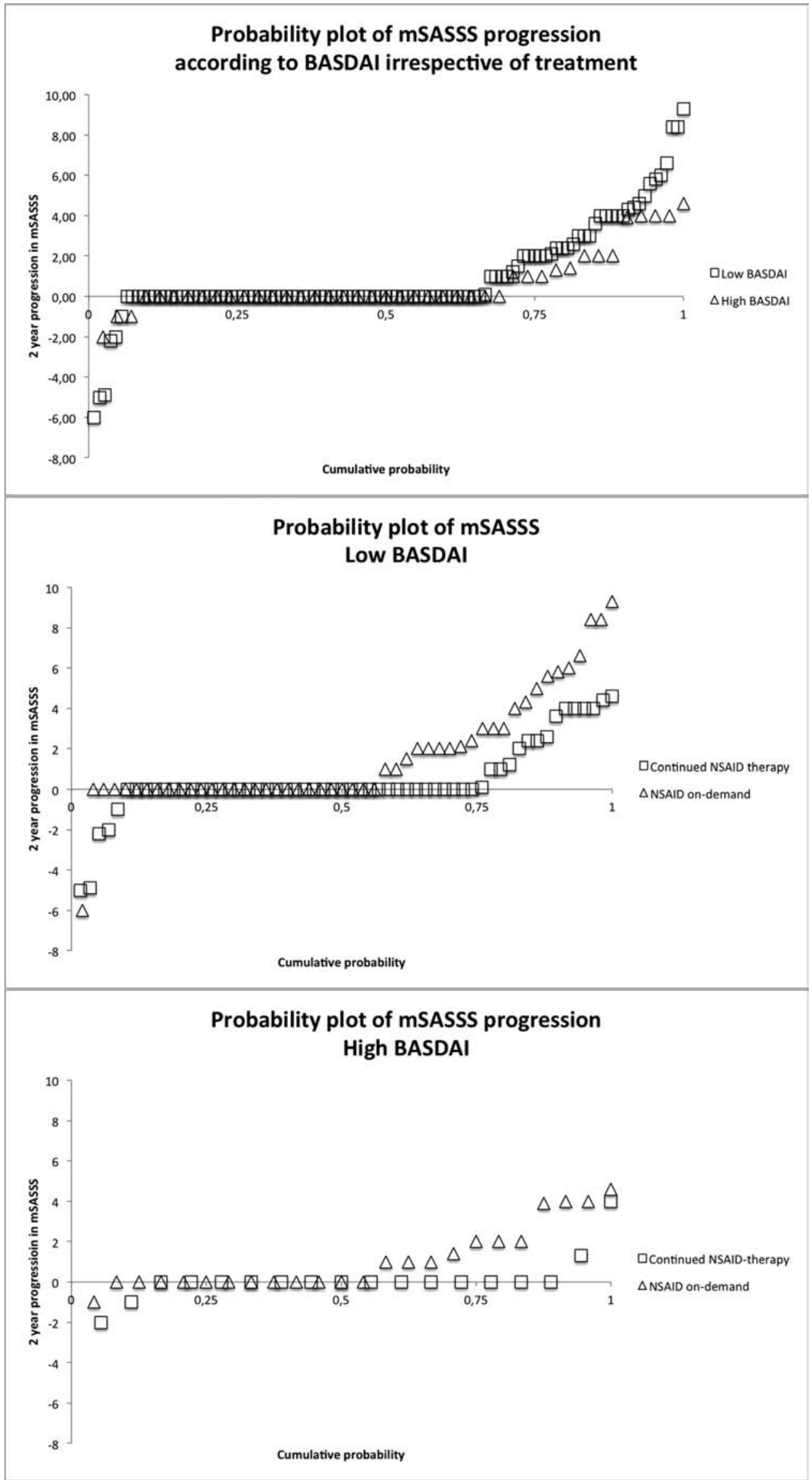

Figure 1 (continued) 


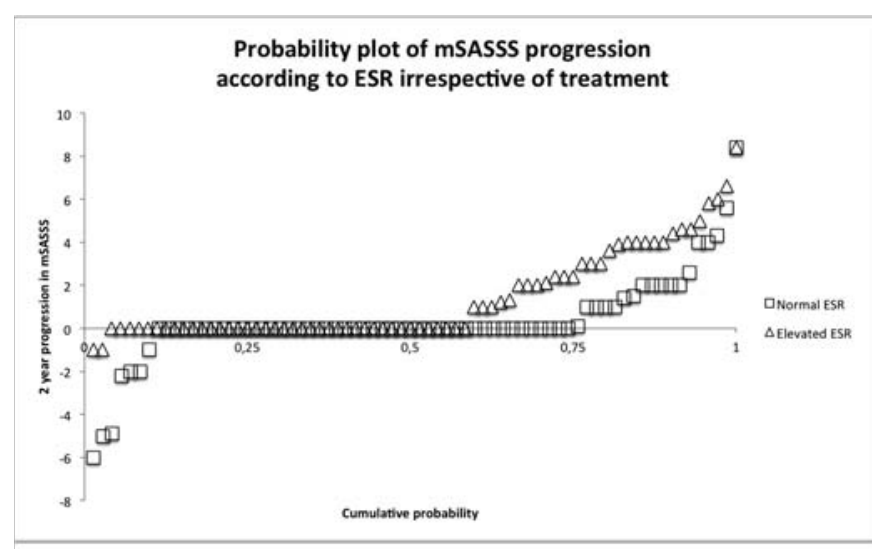

Probability plot of mSASSS progression Normal ESR

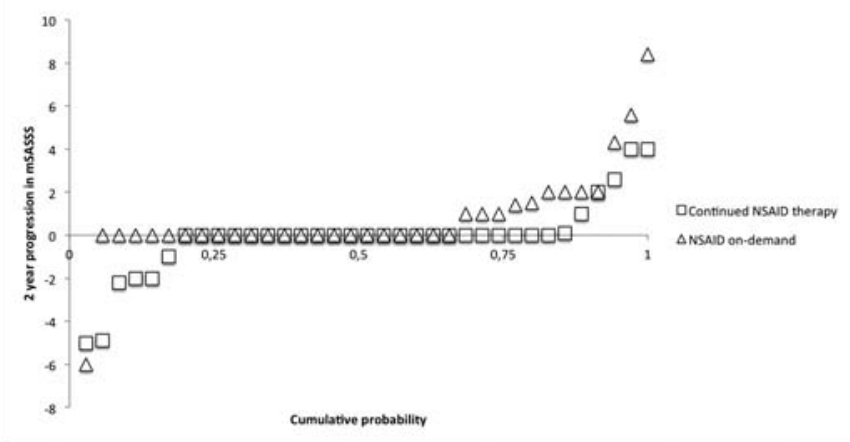

Probability plot of mSASSS progression Elevated ESR

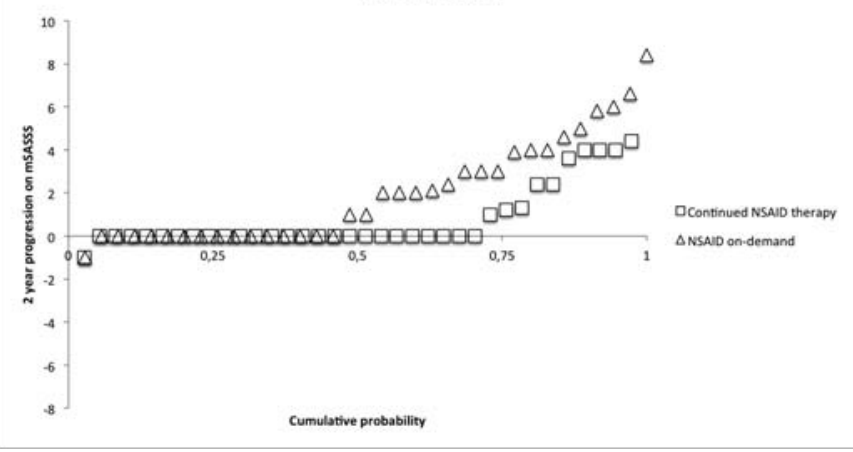

Figure 1 (continued)

(figure 1C) on radiographic progression was not modified by treatment mode since the effect of continuous treatment was similar in the BASDAI high versus BASDAI low group. When testing BASDAI with a cut-off value of 3 , the same pattern was seen.

In contrast to ta-CRP, patients with an elevated ta-ESR $(>12$ $\mathrm{mm} / \mathrm{h}$ ) (figure 1D) had, irrespective of the mode of NSAID therapy, a higher rate of radiographic progression than patients with a normal ta-ESR ( $\leq 12 \mathrm{~mm} / \mathrm{h})$. But in line with observations regarding CRP and ASDAS-CRP, this effect of ESR on radiographic progression was modified by the mode of NSAID treatment: the most effect of continuous NSAID treatment was seen in the patients with elevated ta-ESR.

Figure 1E, at last, looks at radiological progression in relation to ta-ASDAS-ESR. There was no difference in mSASSS progression when comparing low and elevated ASDAS-ESR levels irrespective of treatment (similar to the results in CRP, BASDAI and ASDASCRP). But the effect of ASDAS-ESR on radiographic progression

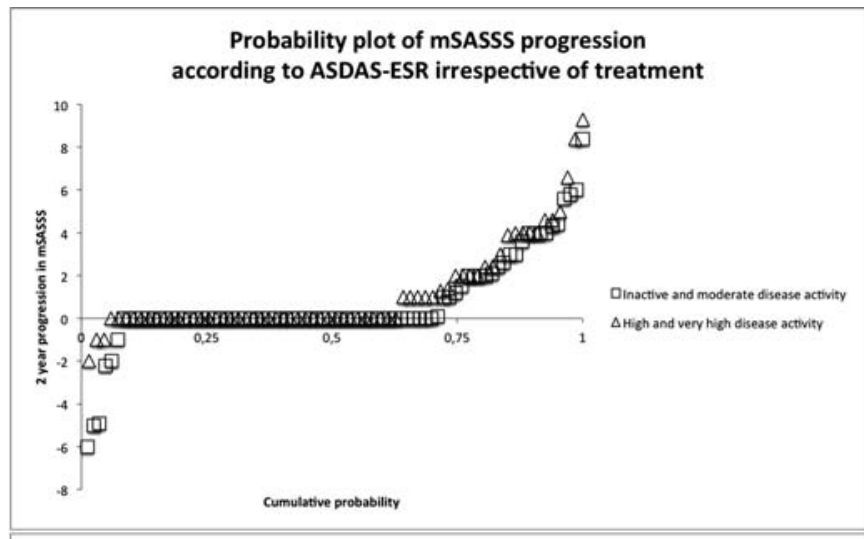

Probability plot of mSASSS progression Low ASDAS-ESR

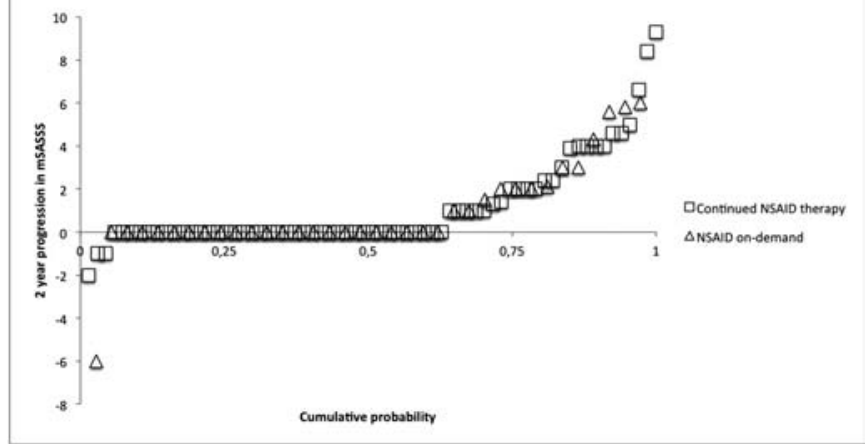

Probability plot of mSASSS progression High ASDAS-ESR

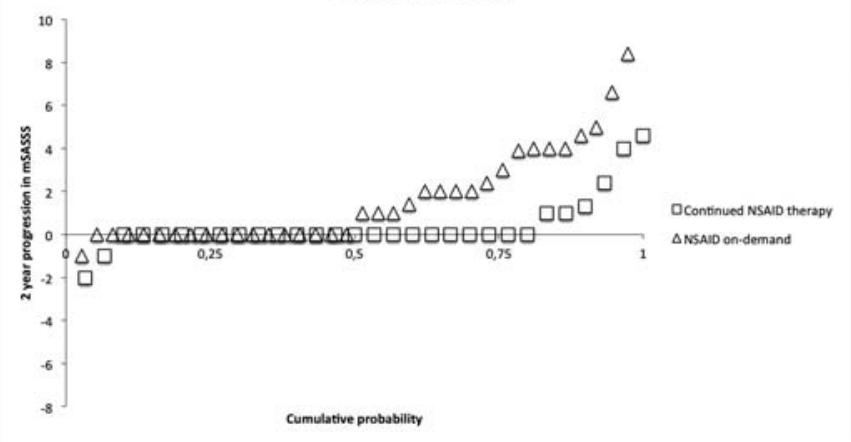

was importantly modified by treatment mode: unlike the situation in the ASDAS-ESR low group, in the ASDAS-ESR high group patients on continuous NSAIDs had far less radiographic progression than patients in the NSAIDs on-demand group (similar to the results in CRP, ESR and ASDAS-CRP).

\section{Statistical justification}

Table 2 shows the radiological progression according to subgroups. Patients were analysed according to subgroups, and according to the treatment arm they were allocated to (continuous or on-demand NSAID therapy). Radiological progression was analysed both as a continuous variable (using the $\delta$ mSASSS) and as a dichotomous variable (at a cut-off level of at least 2 mSASSS units progression).

Ignoring treatment allocation, only ta-ESR had a statistically significant impact on radiographic progression, both in the analysis with continuous progression scores and in the analysis with dichotomised progression scores. 
Table 2 Radiological progression per subgroup

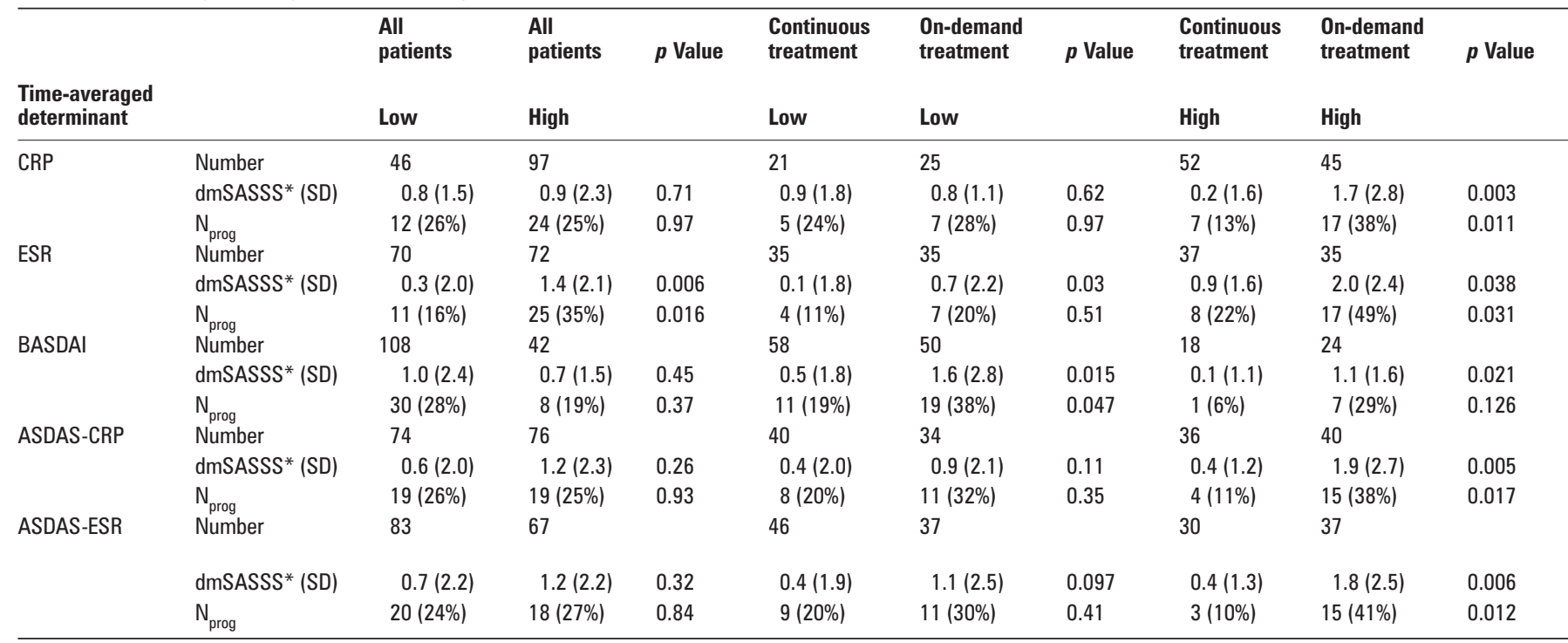

*Mean (SD) value of $\delta$ modi ed stoke ankylosing spondylitis spine score (dmSASSS) in this (sub) group, de ned as the difference between the modi ed Stoke Ankylosing Spondylitis Spine Score (mSASSS) at month 0 and month 24.

$\mathrm{N}_{\text {is }}$ is the number (percentage) of participants in this (sub) group with a progression score on the mSASSS of 2 or more.

ASDASS, ankylosing spondylitis disease activity score; BASDAl, Bath ankylosing spondylitis disease activity index; CRP, C reactive protein; ESR, erythrocyte sedimentation rate.

When the patient groups were analysed according to low versus high values for the time-averaged determinants of radiographic progression, in the groups with low values there were sporadically statistically significant differences between treatment group allocations (eg, an effect of treatment mode on radiographic progression analysed as a continuous variable in the ESR low group). In the groups with high values, however, all subgroups showed statistically significant differences between treatment group allocations in both the analysis with continuous progression scores and in the analysis with dichotomised progression scores.

\section{Regression analysis}

Tables 3 and 4 show regression analysis models for the ESR group. Both the linear regression model and the logistic model show that radiological progression is positively associated with ta-ESR. Both models also show that continuous NSAID treatment neutralises the negative effect of inflammation (high taESR). Since no significant statistical interaction was found, NSAIDs do not appear to have a different mechanism of action in patients with high versus low ta-ESR. We tested the predictive value of the mSASSS at baseline and this was highly significant in both models; however, it did not influence the predictive effect of ESR or the NSAID treatment effect (data not shown).

Regression analyses of CRP, BASDAI, ASDAS-ESR and ASDAS-CRP groups showed similar trends, but the contribution of these variables was not statistically significant.

\section{DISCUSSION}

In this study, we did additional post hoc analyses in a clinical trial that compared continuous NSAID treatment and ondemand NSAID treatment, which was published previously. ${ }^{3}$ We provided evidence that the progression-inhibitory effects of continuous use of NSAIDs in comparison with NSAID use on-demand is more pronounced in patients with elevated taCRP levels, elevated ta-ESR, high ta-ASDAS-CRP and high taASDAS-ESR. This effect is totally dependent on acute phase reactants as a means of inflammation, since it was not seen with
Table 3 Linear regression analysis* on 2-year progression scores of the modi ed Stoke Ankylosing Spondylitis Spine Score (mSASSS)

\begin{tabular}{|c|c|c|c|c|}
\hline & Variable & $\begin{array}{l}\text { Regression } \\
\text { coefficient }\end{array}$ & $p$ Value & Standardised $\beta$ \\
\hline Model 1 & $\begin{array}{l}\text { ESR group } \\
\text { (high) }\end{array}$ & $0.42\left(\begin{array}{lll}0.14 & 0.69\end{array}\right)$ & 0.004 & \\
\hline \multirow[t]{2}{*}{ Model 2} & $\begin{array}{l}\text { ESR group } \\
\text { (high) }\end{array}$ & $0.42\left(\begin{array}{ll}0.15 & 0.69\end{array}\right)$ & 0.002 & 0.25 \\
\hline & $\begin{array}{l}\text { Treatment } \\
\text { (continuous) }\end{array}$ & $-0.43\left(\begin{array}{ll}-0.70 \quad 0.16\end{array}\right)$ & 0.002 & -0.25 \\
\hline Model 3 & $\begin{array}{l}\text { ESR group } \\
\text { (high)X } \\
\text { treatment } \\
\text { (continuous) }\end{array}$ & $-0.26\left(\begin{array}{ll}-0.65 & 0.13\end{array}\right)$ & 0.186 & \\
\hline
\end{tabular}

The analysis was performed using van der Waerden-normalised 2-year mSASSS change scores.

ESR, erythrocyte sedimentation rate.

the fully patient oriented measure of BASDAI. Here, continuous use had a similar positive effect on slowing radiological progression in patients with high versus low ta-BASDAI.

When not taking into account their NSAID treatment, there seemed to be no difference in radiological progression between participants with normal (or low) and elevated ta-CRP, ta-BASDAI, ta-ASDAS-CRP and ta-ASDAS-ESR. In participants with elevated ta-ESR, however (irrespective of treatment), there appeared to be a higher rate of structural progression than in participants with normal ta-ESR.

Taking this information together, continued inflammation in this study represented by ESR, CRP or the combined index ASAS-ESR and ASDAS-CRP plays an important role in radiographic progression. Most importantly, this means we would be able to select patients who may benefit more from continuous use of NSAIDs with regards to radiographic progression.

Using regression analysis, we have shown that the continuous use of NSAIDs can almost completely counteract the negative influence of high ESR on structural damage. Moreover, there is no indication that NSAIDs have a different mechanism of action in patients with high versus those with low ESR (no statistical 
Table 4 Logistic regression analysis on 2-year progression scores (cut-off: 2 units) of the modi ed Stoke Ankylosing Spondylitis Spine Score (mSASSS)

\begin{tabular}{llll}
\hline & Variable & OR (95\% CI) & p Value \\
\hline Model 1 & ESR group (high) & $2.9(1.3$ to 6.4$)$ & 0.011 \\
Model 2 & ESR group (high) & $3.0(1.3$ to 7.0$)$ & 0.014 \\
& Treatment (continuous) & $0.36(0.16$ to 0.81$)$ & 0.008 \\
Model 3 & ESR group (high)X treatment & $0.57(0.11$ to 3.0) & 0.566 \\
& (continuous) & & \\
\hline
\end{tabular}

ESR, erythrocyte sedimentation rate.

interaction), and thus there seems to be an important role for a prostaglandin-mediated mechanism that is independent of the role of inflammation in the formation of syndesmophytes in AS.

The contributory role of inflammatory processes in the progression of structural damage found in this trial is similar to what was found recently in cohort studies. ${ }^{7} 8$ This study, however, is the first to show inhibition in specific subgroups, which may allow the development of treat-to-target guidelines for AS.

This study definitely has its limitations. Although the analyses were hypothesis-driven, they have the disadvantage of post hoc analyses, and the results need to be confirmed. Confirmatory data from the GESPIC-cohort are recently published, but further studies are needed in other prospective cohorts to confirm these findings. ${ }^{4}$ Since we have created several subgroups, numbers in some groups were sometimes low. Also, the results shown in the probability plots did not always match with the differences in radiological progression in the diverse subgroups that were found to be significant.

An intriguing question remains why TNF-blocking drugs, which rapidly restore CRP levels and ESR levels to normal in patients with AS, do not inhibit radiographic progression, ${ }^{10-12}$ while this study and other analyses unequivocally demonstrate that ESR (and to a lesser extent CRP) is to some degree a driver of radiographic progression in AS. A study performed by Haroon et al, for example, presents evidence that normalisation of CRP in patients using TNF-blockers does not slow radiological progression. ${ }^{8}$ Further, as said, this finding suggests that there are inflammation-independent mechanisms, sensitive to the effects of NSAIDs, which contribute to the process of syndesmophyte formation. Elaborating on this from a clinical perspective, this finding gives rise to the question as to whether there is a value in combining TNF-blocking agents with NSAIDs. Therefore, other studies evaluating the optimal use of NSAIDs in combination with TNF-blocking drugs in patients with elevated CRP are required.

In conclusion, patients with elevated acute phase reactants seem to benefit most from continuous treatment with NSAIDs. The application of continuous therapy with NSAIDs in patients with elevated acute phase reactants may lead to an improved benefit to risk ratio of these drugs, although it remains important to weigh the risk and benefit in individual patients.

Contributors All authors participated in the design of the analyses. FK, RBML and DvdH performed the analyses. All authors participated in drafting the paper and finally all authors approved the final manuscript.

Competing interests None.
Provenance and peer review Not commissioned; externally peer reviewed.

\section{REFERENCES}

1. Machado $\mathbf{P}$, Landewé R, Braun J, et al. A stratified model for health outcomes in ankylosing spondylitis. Ann Rheum Dis 2011;70:1758-64.

2. Braun J, van den Berg R, Baraliakos X, et al. 2010 update of the ASAS/EULAR recommendations for the management of ankylosing spondylitis. Ann Rheum Dis 2011;70:896-904.

3. Wanders A, van der Heijde D, Landewé R, et al. Nonsteroidal antiinflammatory drugs reduce radiographic progression in patients with ankylosing spondylitis: a randomized clinical trial. Arthritis Rheum 2005;52:1756-65.

4. Poddubnyy D, Franklin B, Rudwaleit M, et al. Effect of non-steroidal antiinflammatory drugs on radiographic spinal progression in patients with axial spondyloarthritis: results from the GErman SPondyloarthritis Inception Cohort (GESPIC). Ann Rheum Dis. 29 March 2012. [epub ahead of print]

5. van Tubergen A, Ramiro S, van der Heijde D, et al. Development of new syndesmophytes and bridges in ankylosing spondylitis and their predictors: a longitudinal study. Ann Rheum Dis 2012;71:518-23.

6. Maksymowych WP, Landewé R, Conner-Spady B, et al. Serum matrix metalloproteinase 3 is an independent predictor of structural damage progression in patients with ankylosing spondylitis. Arthritis Rheum 2007;56:1846-53.

7. Poddubnyy D, Haibel $\mathrm{H}$, Listing J, et al. Baseline radiographic damage, elevated acute phase reactants and cigarette smoking status predict radiographic progression in the spine in early axial spondyloarthritis. Arthritis Rheum. 29 Nov 2011. [epub ahead of print]

8. Haroon N, Maksymowych W, Rahman P, et al. Radiographic severity in ankylosing spondylitis is associated with polymorphism in large multifunctional peptidase 2 (LMP2) in the SPARCC cohort. Arthritis Rheum 2011.

9. Heiland GR, Appel H, Poddubnyy D, et al. High level of functional dickkopf-1 predicts protection from syndesmophyte formation in patients with ankylosing spondylitis. Ann Rheum Dis 2012;71:572-4.

10. van der Heijde D, Landewé R, Baraliakos X, et al. Radiographic findings following two years of infliximab therapy in patients with ankylosing spondylitis. Arthritis Rheum 2008;58:3063-70.

11. van der Heijde D, Landewé R, Einstein S, et al. Radiographic progression of ankylosing spondylitis after up to two years of treatment with etanercept. Arthritis Rheum 2008;58:1324-31.

12. van der Heijde D, Salonen D, Weissman BN, et al. Assessment of radiographic progression in the spines of patients with ankylosing spondylitis treated with adalimumab for up to 2 years. Arthritis Res Ther 2009;11:R127.

13. Smolen JS, Aletaha D, Bijlsma JW, et al. Treating rheumatoid arthritis to target: recommendations of an international task force. Ann Rheum Dis 2010;69:631-7

14. Landewé $\mathbf{R}$, Dougados $M$, Mielants $H$, et al. Physical function in ankylosing spondylitis is independently determined by both disease activity and radiographic damage of the spine. Ann Rheum Dis 2009;68:863-7.

15. Dougados M, Béhier JM, Jolchine I, et al. Efficacy of celecoxib, a cyclooxygenase 2-specific inhibitor, in the treatment of ankylosing spondylitis: a six-week controlled study with comparison against placebo and against a conventional nonsteroidal antiinflammatory drug. Arthritis Rheum 2001;44:180-5.

16. Garrett S, Jenkinson T, Kennedy LG, et al. A new approach to defining disease status in ankylosing spondylitis: the Bath Ankylosing Spondylitis Disease Activity Index. J Rheumatol 1994;21:2286-91.

17. Wanders AJ, Landewé RB, Spoorenberg A, et al. What is the most appropriate radiologic scoring method for ankylosing spondylitis? A comparison of the available methods based on the Outcome Measures in Rheumatology Clinical Trials filter. Arthritis Rheum 2004;50:2622-32.

18. van der Heijde D, Lie E, Kvien TK, et al. ASDAS, a highly discriminatory ASASendorsed disease activity score in patients with ankylosing spondylitis. Ann Rheum Dis 2009;68:1811-8.

19. Machado P, Landewé R, Lie E, et al. Ankylosing Spondylitis Disease Activity Score (ASDAS): defining cut-off values for disease activity states and improvement scores. Ann Rheum Dis 2011;70:47-53.

20. Landewé $\mathbf{R}$, van der Heijde D. Radiographic progression depicted by probability plots: presenting data with optimal use of individual values. Arthritis Rheum 2004;50:699-706. 